\title{
DWORKIN E POSNER ACERCA DA EXISTÊNCIA DE RESPOSTAS CERTAS PARA AS QUESTÕES JURÍDICAS: A RECONSTRUÇÃO DE UM DEBATE
}

DWORKIN AND POSNER ON THE EXISTENCE OF RIGHT ANSWERS TO LEGAL QUESTIONS: THE RECONSTRUCTION OF A DEBATE

\author{
Ana Carolina da Costa e Fonseca*
}

RESUMO - Dworkin respondeu afirmativamente à pergunta título do seu texto "Não existe mesmo nenhuma resposta certa em casos controversos?". Posner criticou Dworkin e respondeu a mesma pergunta negativamente. Discute-se neste artigo as diferentes maneiras como cada filósofo entendeu a pergunta que acarreta diferentes respostas a ela, isto é, de que modo diferenças na concepção do que é o Direito acarretam diferenças a respeito da existência de respostas certas para questões jurídicas.

PALAVRAS-CHAVE - Ronald Dworkin. Richard Posner. Respostas certas. Questões jurídicas.

ABSTRACT - Dworkin responded in the affirmative to the title question of his text "Is there really no right answer in hard cases?". Posner criticized Dworkin and answered the same question in the negative. This article discusses the different ways in which each philosopher understood the question, and how they lead to different answers to it; that is, in what way differences in the conception of Law entail differences in the existence of correct answers to legal questions.

KEYWORDS - Ronald Dworkin. Richard Posner. Right answers. Legal questions.

* Professora de Filosofia na Universidade Federal de Ciências da Saúde de Porto Alegre (UFCSPA) e de Filosofia do Direito na Faculdade do Ministério Público (FMP). Bacharela, Mestra e Doutora em Filosofia (UFRGS), Bacharela em Direito (UFRGS). E-mail: <anacf@ufcspa.edu.br>.

\begin{tabular}{|l|l|l|l|l|l|}
\hline Veritas & Porto Alegre & v. 56 & n. 3 & set./dez. 2011 & p. 63-71 \\
\hline
\end{tabular}


1. "Não existe mesmo nenhuma resposta certa em casos controversos?"1 (Is there really no right answer in hard cases?), de Ronald Dworkin, e "Há respostas certas para questões jurídicas?"2 (Are there right answers to legal questions?), de Richard Posner, são artigos que tratam, ao menos aparentemente, sobre o mesmo tema. Ambos discutem se há respostas certas para questões jurídicas. Dworkin responde afirmativamente. Posner critica Dworkin e responde negativamente. O surpreendente é que, apesar das respostas serem contrárias, ambos estão corretos. Este artigo visa a esclarecer de que modo ambos os filósofos podem estar corretos apesar de defenderem posições opostas sobre a mesma questão.

2. Posner inicia seu artigo afirmando que "Ronald Dworkin desafiou o ceticismo jurídico ao argumentar que há respostas certas até mesmo para as mais difíceis e controvertidas questões jurídicas". ${ }^{3} \mathrm{O}$ senso comum diria, tanto no Brasil, quanto nos Estados Unidos que existe um certo grau de insegurança em relação às decisões que serão tomadas por juízes quando casos concretos lhes são apresentados, de modo que ninguém ousa fazer previsões sobre o conteúdo de decisões judiciais. A insegurança jurídica pode ser descrita como ceticismo quanto à previsibilidade do conteúdo das decisões. Afirmar que há respostas certas em todos os casos, o que inclui casos difíceis e controversos, é contrário ao senso comum. Apesar de a Filosofia ser uma maneira de pensar para além do senso comum, não pode se furtar de dar conta dele.

Dworkin defende que sempre existem respostas certas para casos controversos. O problema, segundo Dworkin, envolve principalmente dois aspectos: i) saber "se os juízes sempre têm poder de decidir casos controversos"4 e ii) saber "se existe o que os filósofos chamam de 'lacunas' no Direito". ${ }^{5}$ Dworkin responde que defende uma "visão impopular", segundo a qual pode haver "uma [e apenas uma] resposta certa" para questões judiciais. ${ }^{6}$

Dado o modo de funcionamento do sistema jurídico norte-americano, decisões judiciais se fundamentam, basicamente, em precedentes. Questões difíceis, ou hard cases, são casos de difícil solução para o julgador que se depara com um caso concreto. Para a aplicação de precedentes no direito anglo-saxão é necessário identificar no caso a ser decidido os mesmos elementos que motivaram a decisão tomada no

\footnotetext{
Em Uma questão de princípio, p. 175-216.

Em Problemas de Filosofia do Direito, p. 263-293.

POSNER, Richard. Problemas de Filosofia do Direito, p. 263

DWORKIN, Ronald. Uma questão de princípio, p. 175.

DWORKIN, Ronald. Uma questão de princípio, p. 175.

DWORKIN, Ronald. Uma questão de princípio, p. 175.
} 
passado. Se não houvesse precedentes, aparentemente não haveria fundamento para que o juiz tomasse uma decisão no presente, o que poderia justificar que se questionasse a legitimidade para a tomada de decisão no caso concreto. Disso decorre o segundo aspecto apontado por Dworkin, a existência de lacunas no direito. Haveria lacunas quando houvesse um caso concreto para o qual inexistisse uma resposta no ordenamento jurídico. Pode-se conceber os sistemas jurídicos ou como abertos, nos quais sempre se pode introduzir mais uma norma jurídica, havendo, pois, desde o início, a expectativa de existência de lacunas; ou como fechados, neste caso, entende-se que a existência de regras que determinam o procedimento a ser seguido para a produção de novas normas jurídicas faz com que normas futuras estejam implicitamente presentes nos ordenamentos jurídicos que prevêem mecanismos de criação de novas normas. ${ }^{7}$

A tese de que em alguns casos uma questão de Direito não tem resposta tem duas possibilidades de formulação, conforme Dworkin: i) pode não haver resposta certa porque ser verdadeiro ou falso pode não esgotar o espaço lógico ${ }^{8}$, de modo que o princípio de bivalência não poderia ser aplicado; ou ii) os conceitos podem ser imprecisos porque a linguagem é inevitavelmente imprecisa.

O princípio da bivalência ${ }^{9}$ estabelece que, dada qualquer proposição, ela será ou verdadeira ou falsa. ${ }^{10} \mathrm{O}$ espaço lógico é constituído pelas

7 Vários desses problemas são discutidos por Claus-Wilhelm Canaris em Pensamento sistemático e conceito de sistema na ciência do Direito.

8 DWORKIN, Ronald. Uma questão de princípio, p. 177-178.

9 O "[p]rincípio da bivalência é o princípio que estabelece a atribuição ao que é dito mediante cada sentença de determinada linguagem um e somente um de dois valoresde-verdade", conforme Fernando Fleck, O problema dos futuros contingentes, p. 44-45. Os valores de verdade são: verdadeiro e falso. Conforme o princípio da bivalência, uma sentença pode ser dita ou verdadeira, ou falsa. O princípio do terceiro excluído estabelece que não há outra opção para além dos valores de verdade verdadeiro e falso.

10 O problema que decorre deste princípio é o dos futuros contingentes. Se uma proposição é verdadeira, ela será sempre verdadeira. Não é possível que seu valor de verdade mude. O mesmo vale em caso de falsidade da proposição. De modo que se é verdade que amanhã haverá uma batalha naval, é desde sempre verdadeiro que amanhã haverá uma batalha naval. Se hoje for verdadeiro que amanhã haverá uma batalha naval, não é possível que amanhã não haja uma batalha naval, do que se segue estar hoje determinado que amanhã haverá uma batalha naval. O futuro não seria contingente, isto é, eventos futuros não poderiam ocorrer ou não ocorrer, e estaria desde sempre determinado o que ocorreria, pois desde sempre haveria um e apenas um valor de verdade para cada proposição. A tese da bivalência supõe que todas as questões têm uma resposta correta, mesmo que não se saiba qual. A versão clássica deste problema está apresentada por Aristóteles em De interpretatione, 9. Para uma explicação mais detalhada deste problema, leia-se "O problema dos futuros contingentes", de Fernando Pio de Almeida Fleck. 
situações que podem existir na realidade dado um certo conjunto de coisas. Uma questão de direito poderia não ter resposta certa, se ser dita verdadeira ou falsa não fossem as duas únicas respostas possíveis para o que se poderia dizer de tal questão. Neste caso, o espaço lógico da questão permite que se diga algo para além de "verdadeiro" ou "falso" acerca da questão, de modo que o princípio da bivalência não se aplicaria a elas. Evidentemente, neste caso, seria necessário explicar como o princípio da bivalência não se aplicaria, o que não cabe ser discutido neste artigo.

Conforme a segunda formulação, a imprecisão, constitutiva da linguagem, justificaria a inexistência de certeza para muitas questões jurídicas. Afirmar, por exemplo, que Charles é um homem corajoso, conforme o exemplo apresentado por Dworkin, seria difícil devido à imprecisão do que significa ser corajoso. Por outro lado, alguns filósofos entendem que não existe nenhuma resposta certa para a questão de se Charles era corajoso, se Charles estiver morto e se nunca se deparou com qualquer situação de perigo durante sua vida. Seria errado dizer que um homem foi ou não corajoso, se não pudermos ter provas pertinentes à questão do que ele era. Neste caso, o espaço lógico não estaria totalmente coberto. $\mathrm{E}$ a dificuldade em atribuir valor de verdade à afirmação de que Charles é corajoso não decorreria da imprecisão da linguagem, mas de uma impossibilidade fática. ${ }^{11}$

3. A aparente contradição entre Posner e Dworkin decorre de uma confusão entre resposta correta (avaliação jurídica da resposta) e resposta verdadeira (avaliação fática da resposta). No âmbito jurídico, podese dizer que uma resposta é correta ou incorreta. Pode-se discutir se a decisão do Supremo Tribunal Federal, ao julgar a ação direta de inconstitucionalidade (ADI) 4277 e a Arguição de Descumprimento de Preceito Fundamental (ADPF) 132, que reconheceu a união estável para casais do mesmo sexo, é correta ou não. Neste caso, a correção será avaliada dos pontos de vista jurídico e moral, e uma avaliação jurídica não deixa de ser, em muitos casos, uma avaliação moral. Não cabe, contudo, dizer que a decisão é verdadeira ou falsa. Pode-se discutir se é verdade ou não que o STF decidiu o que decidiu e, neste caso, estaríamos expressando dúvida ou certeza quanto ao resultado da decisão. Provas apresentadas para corroborar ou não uma tese são meios para que se entenda se uma tese é ou verdadeira ou falsa. A correção ou não da tese, contudo, é uma questão jurídica.

${ }_{11}$ DWORKIN, Ronald. Uma questão de princípio, p. 178-179. Dworkin utiliza o exemplo de Michael Dummett. 
Como veremos adiante, Posner divide sua avaliação entre questões de fato e questões de direito. Descrições de fatos podem ser verdadeiras ou falsas. Decisões sobre questões de fato podem ser corretas ou incorretas. Questões de direito podem ser apenas corretas ou incorretas.

4. Seguindo Dworkin e pensando o Direito não como um conjunto de normas independentes entre si, mas como um sistema jurídico, a inexistência de uma norma a respeito de um determinado caso concreto acarreta a aplicação da norma geral conclusiva, de modo que haveria resposta mesmo em caso de silêncio da lei ${ }^{12}$; por isso, ele defende que sempre existe uma e apenas uma resposta correta, mesmo nos casos controversos. Eis uma resposta característica de quem tem uma teoria do direito como integridade. Dworkin conclui que:

[u]ma proposição de Direito... é verdadeira se a melhor justificativa que se pode fornecer para o conjunto de proposições de Direito tidas como estabelecidas fornece um argumento melhor a favor dessa proposição que a favor da proposição contrária, ... mas é falsa se essa justificativa fornece um argumento melhor a favor dessa proposição contrária. ... pode existir uma resposta correta para a questão... mesmo que a resposta não possa ser demonstrada. ${ }^{13}$

Afirmar que há uma resposta correta não implica que se possa determinar qual é esta resposta. Sabe-se, ao menos, que por negação da proposição correta, tem-se uma proposição incorreta.

Defendida a tese da integridade, Dworkin desafia seus críticos a apresentarem um caso concreto de questão jurídica que não tenha uma resposta certa. Não basta discutir, no plano teórico, se é possível ou não que haja questões jurídicas sem resposta certa. É preciso indicá-las. E não basta indicar, é preciso que a incerteza do caso seja justificada com argumentos filosóficos.

A questão, portanto, de se existem casos sem nenhuma resposta certa em um determinado sistema jurídico - e se tais casos são raros ou numerosos - não é uma questão empírica comum. Acredito que tais casos, se é que existem, devem ser extremamente raros nos Estados Unidos e na Grã-Bretanha. Alguém que conteste isso.... [não] terá êxito se tentar encontrar exemplos efetivos de casos sem nenhuma resposta certa numa investigação, caso a caso, dos relatos jurídicos. Cada relato de caso contém um parecer sustentando que, na comparação, um lado tem o melhor argumento no debate jurídico. .... O argumento de que estou errado, portanto, deve ser um argumento filosófico. Deve contestar

${ }_{12}$ DWORKIN, Ronald. Uma questão de princípio, p. 185.

${ }^{13}$ DWORKIN, Ronald. Uma questão de princípio, p. 211. 
minha suposição de que um sistema jurídico complexo e abrangente é improvável que duas teses difiram a ponto de exigir respostas diferentes em algum caso e, ainda assim, adequar-se igualmente bem ao conteúdo jurídico relevante. Deve fornecer e defender alguma ideia de ceticismo, ou de indeterminação na teoria moral, que torne plausível supor que nenhuma de tais teorias pode ser preferida em detrimento da outra com base na moralidade política. Não acho que tal argumento tenha sido fornecido, apesar de certamente não ter demonstrado que isso seja impossível. ${ }^{14}$

Dworkin inverte o ônus da prova. Não cabe a ele provar a existência de respostas certas para questões jurídicas, prova que, em princípio, parece ser muito difícil, senão, impossível. Cabe a seus críticos provarem o contrário pela exibição de um caso concreto e de justificação filosófica do conteúdo incerto de tal caso, adotada a teoria da integridade do ordenamento jurídico.

5. Posner é um desses críticos. Contudo, não aceita o desafio feito por Dworkin, apesar de, claramente, não ter ficado convencido com seus argumentos, que me limitei a apresentar no que me pareceu necessário para compreendermos por que e em que termos Posner discorda de Dworkin. Dá-se voz a Posner para compreendermos por que entende que Dworkin está errado.

Saber se Ricardo III matou a princesa é uma questão de fato. ${ }^{15}$ Responder a esta questão exige conhecimento do que ocorreu e não conhecimento filosófico. Há apenas uma resposta certa para esta questão: ou Ricardo III matou, ou não matou a princesa Anne. Esta resposta é do tipo verdadeiro ou falso. Evidentemente, alguém poderia dizer que ele não matou, por não ter feito isso com as próprias mãos, mas que mandou matá-la. Esta objeção, contudo, se refere apenas à eventual falta de clareza da questão. Facilmente podemos reformular a questão para distinguir matar com as próprias mãos de mandar matar e, deste modo, acabar com a alegada ambiguidade. Questões de direito, contudo, não são do tipo verdadeiro ou falso. Como nos diz Posner: "[s]oa estranho.... perguntar se 'é verdade' que a Décima Quarta Emenda significa isso ou aquilo." ${ }^{16}$ Há boas ou más interpretações do texto constitucional. Não há, contudo, interpretações verdadeiras ou falsas.

Para um operador do Direito, "se a resposta for inacessível, é como se não houvesse resposta certa...."17 Para questões discutidas em

${ }_{14}$ DWORKIN, Ronald. Uma questão de princípio, p. 216.

15 Dworkin e Posner discutem esta questão em seus artigos.

16 POSNER, Richard. Problemas de Filosofia do Direito, p. 265.

17 POSNER, Richard. Problemas de Filosofia do Direito, p. 265. 
tese, ou para questões de fato, não parece ser um problema não haver respostas verdadeiras ou falsas. No caso da aplicação do Direito, o problema se torna ainda pior, pois "um caso jurídico deve ser decidido quando se apresenta". ${ }^{18}$ Não podemos esperar até que "a verdade" seja descoberta. E em questões de direito, quando devemos pesar os argumentos apresentados, um não necessariamente se apresentará como mais forte do que outro. Se não temos critérios absolutos para determinar qual é a melhor interpretação da lei, tampouco qual é a melhor avaliação dos fatos, se "não é verificável pelos métodos de investigação exata, uma vez que os dados não se prestam à observação experimental, estatística ou, sob outros aspectos, exata"19, então há casos em que não temos respostas certas, ou que, ao menos, não temos como saber se há resposta certa. A incerteza da decisão, neste caso, decorre da incerteza quanto à verdade ou falsidade dos fatos alegados. Não decorre, contudo, da incerteza das questões de direito envolvidas no caso a ser decidido.

6. Há, segundo Posner, três problemas no sistema jurídico norteamericano que concernem à questão da certeza das decisões jurídicas: 1) tribunais não estão em busca apenas da verdade; ${ }^{20} 2$ ) o processo tem uma função terapêutica; ${ }^{21}$ e 3) os advogados atuam como investigadores, ou seja, cabe a eles a produção de provas, o que faz com que quem possa pagar melhores advogados tenha mais chances de vencer o processo. ${ }^{22}$ Discute-se, a seguir, apenas sobre o primeiro problema, pois ele se refere especificamente ao ponto abordado neste artigo.

Há exigência de fundamento nas decisões de juízes e não-exigência de fundamento em decisões de júris. Juízes precisam justificar a motivação da sua decisão. Júris apresentam apenas o resultado de sua decisão, sendo irrelevante a motivação, que pode ser emocional, afetiva, e não precisa ser baseada em evidências ou em convicções jurídicas. Para Posner, a diferença entre juízes e júris no que concerne à motivação e à forma de publicização de suas decisões mostra incerteza quanto às decisões jurídicas. Esta questão, contudo, é irrelevante para Dworkin no que concerne à certeza ou não das respostas para questões jurídicas, pois Dworkin analisa as decisões como resultado. E Posner está preocupado em analisar o próprio resultado, por isso, recorre ao exemplo do julgamento de acusações de bruxaria e de feitiçaria: "Nada, em nenhum tribunal existente, foi mais completamente provado do que

\footnotetext{
18 POSNER, Richard. Problemas de Filosofia do Direito, p. 265.

19 POSNER, Richard. Problemas de Filosofia do Direito, p. 266.

20 POSNER, Richard. Problemas de Filosofia do Direito, p. 275.

21 POSNER, Richard. Problemas de Filosofia do Direito, p. 275-276.

22 POSNER, Richard. Problemas de Filosofia do Direito, p. 276-277.
} 
as acusações de bruxaria e feitiçaria em nome das quais tantas pessoas foram mortas" 23 , com o que pretende relembrar seu leitor da "falibilidade das decisões judiciais sobre questões de fato". ${ }^{24}$ Se pode haver erro nas questões de fato, as decisões que se baseiam em erros estariam igualmente erradas.

Se a incerteza factual é desproporcionalmente característica dos casos levados a juízo (dos quais são extraídos os casos publicados), então, dada a dificuldade de eliminar tal incerteza através dos métodos do processo judicial, podemos esperar que a avaliação dos fatos em decisões judiciais publicadas estejam quase sempre erradas.

A crítica a Dworkin se estende a uma crítica ao próprio sistema jurídico norte-americano. A incerteza quanto às decisões judiciais é reconhecida e incorporada ao próprio sistema jurídico como algo constitutivo e benéfico para a sociedade, como, por exemplo, pela absolvição em caso de dúvidas sobre a autoria e as circunstâncias de um crime. Quanto aos casos concretos, "há um grande número de casos jurídicos nos quais a questão do que aconteceu é indeterminada, e que devem ser resolvidos por uma decisão sobre quem vai arcar com o ônus de apresentar provas ou de convencer quem vai fazer o reconhecimento dos fatos no processo". ${ }^{25}$ No âmbito jurídico, não importa apenas o que aconteceu, como também o que motivou (ou não) o agente. ${ }^{26} \mathrm{~A}$ motição é um elemento fundamentalmente subjetivo. Compreendê-la tampouco é objetivo. Além disso, a própria descrição dos fatos e da motivação, quando relevante, é feita pelos juízes, segundo Posner, de modo a tornarem sua decisão a melhor possível, ${ }^{27}$ sendo mais um elemento indicativo da ausência de objetividade nas decisões. O que parece um fato é que "a certeza é inalcançável na maioria dos julgamentos". ${ }^{28}$ As decisões decorrem de uma avaliação de probabilidade.

7. Poderíamos nos perguntar sobre qual dos dois está, afinal, correto? Ambos? Nenhum? Respondi, no início deste artigo, que ambos estão corretos, não porque o problema contenha, em si, uma contradição, mas porque eles não estão tratando do mesmo problema. As posições de Dworkin e de Posner são irredutíveis porque ambos têm concepções metafísicas distintas acerca da ontologia do Direito. O ponto de partida

23 Posner cita o The devil's dictoinary, em Problemas de Filosofia do Direito, p. 280.

24 POSNER, Richard. Problemas de Filosofia do Direito, p. 280.

25 POSNER, Richard. Problemas de Filosofia do Direito, p. 273.

${ }^{26}$ POSNER, Richard. Problemas de Filosofia do Direito, p. 274.

27 POSNER, Richard. Problemas de Filosofia do Direito, p. 282.

${ }_{28}$ POSNER, Richard. Problemas de Filosofia do Direito, p. 283 e ss. 
de ambos não é neutro e tampouco está sendo discutido. Suas respostas ao que é o Direito são distintas. Consequentemente, posições teóricas que decorrem destas concepções também. Por isso, não há como escolher uma das duas posições sem, efetivamente, adotarmos uma posição que parece descrever melhor o que se entende por Direito. Por Dworkin adotar a tese da integridade do Direito, a resposta a um caso é a resposta certa. Para Posner, a avaliação jurídica não pode se dar de modo independente da avaliação moral. A resposta a uma questão jurídica que por ser única é, para Dworkin, correta, pode, para Posner, não ser moralmente correta. Por ler Dworkin como um defensor de uma interpretação objetiva, Posner o critica. Se lermos cada um conforme sua concepção do que é o Direito, reconhecemos que ambos estão corretos, apesar de e especificamente por conceberem de modo distinto a certeza das respostas às decisões jurídicas.

\section{Referências}

ARISTOTLE. The complete works of. Princeton: Princeton University Press, 1995.

CANARIS, Claus-Wilhelm. Pensamento sistemático e conceito de sistema na ciência do Direito. Lisboa: Fundação Calouste Gulbenkian, 1996.

DWORKIN, Ronald. Uma questão de princípio. São Paulo: Martins Fontes, 2001.

FLECK, Fernando Pio de Almeida. O problema dos futuros contingentes. Porto Alegre: EDIPUCRS, 1997.

INGRAM, David. Filosofia do Direito: conceitos-chave em Filosofia. Porto Alegre: Artmed, 2010.

POSNER, Richard. Problemas de Filosofia do Direito. São Paulo: Martins Fontes, 2007. 